\title{
COVID-19 and access to essential medicine: Discussion paper
}

\begin{abstract}
Pandemics, natural, unnatural and man-made disasters, make it difficult to have normal access to medicines (ATM). However, stringent policies and accurate planning ensures ATM by controlling sky-high medicine prices. The policymakers, healthcare providers and government should consider these recommendations to ensure ATM amid COVID 19: (1) Prioritization of Medicine List; (2) Considering National Essential Medicine List; (3) Dual \& Multisource Contracts; (4) Bulk Procurement System; (5) Review of legislation and procurement policies; (6) Reforms in importation and customs procedures; (7) TradeRelated Aspects of International Property Rights; (8) Controlling medicine prices; (9) Encouraging domestic pharmaceutical production and (10) Effective Monitoring System. The author concludes that these recommendations have implications for equitable access to essential medicine (EM). We call upon the policy makers, the governments, drug regulatory authorities, the big pharma and domestic pharmaceutical companies to accelerate their efforts to ensure equitable and affordable ATM.
\end{abstract}

Volume 8 Issue 6 - 2020

\author{
Mohammad Bashaar \\ Health Policy Analyst and Consultant, SMART Afghan \\ International Training and Consultancy, Afghanistan
}

\author{
Correspondence: Mohammad Bashaar, Health Policy Analyst \\ and Consultant, SMART Afghan International Training and \\ Consultancy, Afghanistan, Tel +93788233865, \\ Email mbasaar@gmail.com
}

Received: November 14, 2020 | Published: December II, 2020

\section{Introduction}

As the world was preparing to celebrate the dawn of a new decade 2020, and the people was struggling with the socio-economic and public health backlogs, the coronavirus disease (COVID-19), emerged in December, 2019, in Wuhan, China, and ruined the hopes of humanity. ${ }^{1}$ The world is still fighting with the devastating effects of AIDS, one of the deadliest viruses in human history. According to reports, the vast majority of people living with HIV (87\%) will be in high-and middle-income countries by $2020 .{ }^{1}$ Despite of AIDs dilemma, the novel and severe acute respiratory syndrome coronavirus 2 (SARS-CoV-2) emerged amid billions people are facing with lack of access to EM, especially with chronic diseases. ${ }^{2}$ Now people are focusing to purchase face masks, hand sanitizers, paying for diagnosis and testing for coronavirus, in addition or despite buying EM.

Research from Jinyintan and Wuhan Pulmonary Hospitals shown that among 54 people died most of them had comorbidity (hypertension, diabetes and coronary heart disease patients). Therefore, in order to decrease the death toll, supply of EM is of paramount to tackle with coronavirus complications. The virus has now spread worldwide and still the confirmed cases continue to rise. The world's largest economy, the United States of America (USA) signed into law an \$8.3 billion emergency spending bill for the Coronavirus response. ${ }^{3}$ In contrast, what would be the response of Low and Middle Income Countries (LMICs), where sparsely budget is allocated for EM. According to $\mathrm{CEO}$ and founder of Masters Specialty Pharma Zulf Masters "two billion of the world's population living in LMICs still does not have access to modern medicine. This is because "big pharma invariably lives in the first world" and "first tier countries still offer the lion's share of their revenue stream." \{Nawrat, $2020 \# 14\}$

The COVID 19 pandemic $\{$ WHO, $2020 \# 15\}$ has spread to almost every country $\{$ WHO, $2020 \# 16\}$. In comparison to high income

${ }^{1}$ https://makemedicinesaffordable.org/en/where-we-work/

${ }^{2} \mathrm{https}$ //accesstomedicinefoundation.org/

${ }^{3}$ https://www.wsj.com/articles/coronavirus-costs-whos-paying-for-allthis-11583317801 countries, LMICs have large populations living in overcrowded conditions; lack of clean water, lack of access to hand sanitizer and other COVID 10 preventive measures are impossible to find. Therefore people living in LMICs will generally not be able to follow the public health advice in regards to coronavirus. The COVID-19 is an alarming threat to public health and also has negative financial and economical implications to LMICs. Despite of its financial devastation, it is affecting nations' macro-economies, hindering the trade, revoking human development accomplishments, crumble the capacity of governments to maintain essential services, plummeting the efficiency and delivery of mega industries, and lastly putting a brake on economic and social development.

Coronavirus does not discriminate and certain groups may be more at risk, but the virus can spread to anyone. On the other hand lamentably, the world especially LMICs are already in the midst of another alarming dilemma: the shortage of essential medicines and medications that are significant for managing COVID-19. ${ }^{2}$ Therefore, in order to effectively respond to COVID-19 requires strong and resolute public-private partnerships with a shared commitment to putting the health and well-being of people first. In addition, the donor agencies and the national health insurance providers in each country should provide full support to health-care providers to develop and implement solutions that will protect their people seeking diagnoses for, and treatment of, COVID-19 from out-of-pocket costs. We seek the active of World Bank, IMF to provide loans and grants to LMICs.

The roles of pharmaceutical companies are indispensible to provide affordable EM to LMICs. If not considered seriously, the COVID-19 will make the people, households and in large will sabotages the 2030 Agenda (SDG 3 "Ensure healthy lives and promote wellbeing for all at all ages"). The aim of this paper is to discuss the negative impact and implications of COVID-19 on access to essential medicines, especially in low and middle-income countries. Further this paper will provide handy and pragmatic steps for policymakers, decision-makers and healthcare providers on measures to ensure access to essential medicines in response to COVID-19. 


\section{Discussion}

Amid declaring the COVID-19 as pandemic, the world especially the LMICs faced with shortages of EM, since paradigm was shifted towards responding COVID-19. The big pharmaceutical and research companies shifted their budgets towards research and making corona virus vaccine.

Due to quarantine, lockdowns and limitation and export bans, the entire supply chain from raw material providers, the pharmaceuticals manufacturers, wholesalers, distributors, retailers and its supply to hospitals, nursing homes, prisons, clinics, and homes through mail-orders are disrupted. ${ }^{3}$ At the large scale the international trade, significant numbers of shipments of medicines and active pharmaceutical ingredients (API) other components and finalized pharmaceutical products (FPPs), health products and vaccines delayed. In addition, stockpiling and storage of medicines by hospitals, citizens and countries made the situation much worsens. On the other hand the medicine prices are heightened due to limitation in the production capacity of pharmaceutical companies and layoff of workers.

Panic, emotional and irrational purchase of medicines has led to inadequate supplies of essential medicines, and these shortages will have potentially devastating consequences for chronic diseases management in LMICs. Lack and shortages include medications that have been said as promising therapies against COVID-19, such as chloroquine and hydroxychloroquine. ${ }^{4}$ Now it is difficult to get hydroxychloroquine to treat rheumatoid arthritis and other autoimmune disorders, since it is used for managing COVID 19. In addition, the market is facing with critical shortage of sedatives such as midazolam and propofol which are required for patients who are being intubated and placed on mechanical ventilation. ${ }^{5}$ Demand for dexamethasone rises after study conducted by University of Oxford, that the medicine can improve the survival rate of COVID-19 patients. ${ }^{6}$

Most of the patients died due to COVID-19, had other associated health problems such as hypertension, diabetes, cancer and chronic pulmonary diseases, cardiovascular disease, immune system deficiency and older age. ${ }^{7-9}$ Therefore, the patients with chronic diseases require regular access to medicine in order tackle with current pandemic. One of main factors ensuring the access to medicine is its affordable prices. In addition, the below recommendations can assist to ensure equitable access to EM meanwhile responding COVID-19.

\section{Recommendations}

It must be ensured that each and every person can equitably access to affordable medicines, especially in this critical situation. The COVID-19 is a wake-up call for policymakers, decision makers and the government to urgently act upon on policies to ensure access to medicines.

a. Prioritization of Medicine List: The healthcare provider at national level is to develop a priority list of medicines, e.g. COVID-19 medicines, medicines for HIV, tuberculosis, noncommunicable diseases (NCDs), epilepsy or mental health and medicines for emergency medical conditions. ${ }^{10}$ However, the pharmaceutical companies are considering the competitive advantage and produce only medicines which has great margin of profit in terms of money.

b. Considering National Essential Medicine List: It is of paramount importance that LMICs should follow the standard WHO guidance to procure medicines listed on their national essential medicine list (NEML) and national essential medicines for children. To prevent shortages of essential medicines, governments should give clear guidance on the use of COVID 19 prophylactic medicines and act now to secure adequate supplies and stocks of essential medicines. ${ }^{11}$

c. Dual \& Multisource Contracts: Medicines that are being purchased from a single supplier are particularly vulnerable; these medicines should be identified and other routes sourced to protect suppliers, including purchase from alternative sources, such as UN agencies or wholesalers. Investigate local production of critical products to reduce reliance on foreign sources.

d. Bulk Procurement System: During the COVID-19 the health agencies must contain the medicine prices by bulk procurement, though it is not sufficient to lower the prices. However, can leverage the ATM.

e. Review of Legislation and Procurement Policies: At policy level, it is required to critically review the current legislation and regulations in order to identify any potential barriers to maintaining supply and implementing the guidance given below. For example, identify what impediments exist to purchasing from international agencies, centralizing procurement or provision of packaging and documents in local languages. Emergency mechanisms for procurement should be in place.

f. Reforms in Importation and Customs Procedures: The central government should review and reform the current pharmaceutical importation procedures and establish a 24/7 services for approving the importation of generic drugs or grant immediate approval for selected generic drugs manufactured in other countries and domestically. ${ }^{2}$

g. Trade-Related Aspects of International Property Rights (TRIPS) flexibilities must be ensured to permit the domestic production of key medicines in case of shortage. ${ }^{10}$

h. Controlling Medicine Prices: Even with enough availability of medicines in the market, the prices of medicines must be controlled to ensure equitable and affordable access to medicine. This could be possible by applying multi-pronged policies. the big pharma must reconsider their policies especially related to costd of research and development (R\&D), as developing new molecules are not that much expensive as they display and even they exaggerates the costs of R\&D\{Light, $2011 \# 13\}\{\mathrm{MSF}$, $2019 \# 17\}$.

i. Encouraging Domestic Pharmaceutical Production: The government should persuade the national manufacturing companies to boost their productions through funding and waiving taxes and tariffs.

j. Effective Monitoring System: A fast-track monitoring system is required to be placed to help prevent and mitigate supply issues with crucial medicines used for treating COVID-19 patients, especially medicines used in intensive care. ${ }^{4}$

\section{Conclusion}

Though the medicine shortage is not felt but it is threatening, considering the COVID 19 strengths so far. It is not possible to fix the

${ }^{4}$ https://www.ema.europa.eu/en/human-regulatory/overview/public-healththreats/coronavirus-disease-covid-19/availability-medicines-during-covid-19pandemic 
current fragile and complex pharmaceutical supply chain in LMICs overnight, and yet we must overcome its limitations rapidly and decisively. And we must act before it is too late and worse. We call upon the policy makers, the governments, drug regulatory authorities, the big pharma and domestic pharmaceutical companies to accelerate their efforts to ensure equitable and affordable ATM.

\section{Funding sources}

No funding received.

\section{Ethics approval and consent to participate}

Not applicable.

\section{Acknowledgments}

None.

\section{Conflicts of interest}

The authors declare that they have no conflict of interest.

\section{References}

1. Zhou F, Yu T, Du R, et al. Clinical course and risk factors for mortality of adult inpatients with COVID-19 in Wuhan, China: a retrospective cohort study. Lancet. 2020;395(10229):1054-1062.
2. Rajkumar SV. Medication Shortages During the COVID-19 Crisis: What We Must Do. Mayo Clin Proc. 2020;95(6):1112-1115.

3. Alexander GC, Qato DM. Ensuring access to medications in the US during the COVID-19 pandemic. JAMA. 2020;324(1):31-32.

4. Lee J. There's scant evidence so far for chloroquine as a COVID-19 drugbut there's already a shortage; 2020.

5. Silverman E. New Covid-19 Problem: Shortages of Medicines Needed for Placing Patients on Ventilators; 2020.

6. Sharma S, Ashtey B. Investigational treatments for COVID-19. Evaluation. 2020;15:13.

7. Jordan RE, Adab P, Cheng K. Covid-19: risk factors for severe disease and death. BMJ. 2020;368:m1198.

8. Zheng YY, Ma YT, Zhang JY, et al. COVID-19 and the cardiovascular system. Nature Reviews Cardiology. 2020;17(5):259-260.

9. Qin C, Zhou L, Hu Z, et al. Dysregulation of immune response in patients with COVID-19 in Wuhan, China. Clinical Infectious Diseases. 2020;71(15):762-768

10. Strengthening the health systems response to COVID-19: technical guidance\# 2: creating surge capacity for acute and intensive care, 6 April 2020. In.: World Health Organization, Regional Office for Europe; 2020.

11. Hopman J, Allegranzi B, Mehtar S. Managing COVID-19 in low-and middle-income countries. JAMA. 2020;323(16):1549-1550. 